\title{
Mutation analysis of structural and non-structural proteins indicated that the death rate of COVID-19 pandemic may significantly reduce by the end of $\mathbf{2 0 2 0}$
}

\author{
Authors: Saakshi Jalali ${ }^{1}$, Bhaskar Bhadra ${ }^{1 *}$ and Santanu Dasgupta ${ }^{1}$
}

1, Synthetic Biology group,

Reliance Corporate Park, Reliance Industries Limited, Navi Mumbai 400701, India

*, corresponding author Bhaskar Bhadra e-mail: Bhaskar.Bhadra@ril.com, Phone: 00912244750885

e-mail ID of authors:

Saakshi.Jalali@ril.com,

Bhaskar.Bhadra@ril.com,

Santanu.Dasgupta@ril.com

INDEX TERMS: COVID-19, SARSCoV-2, Virus mutation, NSP6, S glycoprotein, mutation rate

\begin{abstract}
The outbreak of the infectious and rapidly expanding coronavirus disease 19 (COVID-19) caused by the SARS-CoV-2 virus has led to a devastating effect on public health and the global economy. The daily country-wise updates from the World Health Organization on number of infected cases and death rates show diverse statistics. In this study, we performed a comparative analysis between the COVID-19 death rate and mutation rate for selected structural and non-structural proteins. A total of 7200 genome sequences of SARS-CoV-2 virus from 49 countries were investigated. The mutation rate of specific proteins of SARS-CoV-2 over the last four months (April - July, 2020) was correlated with the death rate across various countries. From our findings, we suggest a significant correlation between the mutation rates of NSP6 and Surface glycoprotein with the death rate. Additional analysis of cumulative mutation rate of these two proteins with the death rate of three major clusters helped us to hypothesize that mutations of these 2 proteins will grow consistently while the death rate would drop below $0.5 \%$ by end of 2020 in cluster I countries. Hence, we propose that with the current mutation rate trend, COVID-19 death rate would significantly weaken by the end of this year.
\end{abstract}

\section{INTRODUCTION}

The COVID-19 pandemic caused by severe acute respiratory syndrome virus (SARS-CoV-2) is a beta-coronavirus containing 29,903 nucleotides-long single-stranded RNA. After the first report at Wuhan, China, in December 2019, the disease was spread over 230 countries within a couple of months. It was believed that, like other beta-coronaviruses, SARS-CoV-2 is a human zoonotic pathogen sharing almost 96\% similarity with BatCoV RaTG13 which was found in horseshoe bats [1]. Over the last couple of decades, viral zoonotic infection [2] caused by avian influenza, chikungunya virus, nipa virus, hantaviruses, SARS-CoV-1, MERS (middle east respiratory syndrome), etc. have significantly impacted human health and economy. It is to be believed that zoonosis viruses evolved through mutations of the viral genome which sometimes changes the structure of surface proteins leading to a change in host specificity.
In the past century, diseases which were acquired from animals wreaked havoc, e.g. 'Spanish flu' and 'Hong Kong flu' causing 50 - 60 million deaths all over the world. In current times, urbanization, increased global travel, changes in land use, and changes in the environment $[3,4]$ has led to the likelihood and spread of infectious diseases. From the past it can be determined that, pandemics like influenza in 1918, 1957, and 1968 years slowly subsided either via acquiring heard-immunity or by loss of infectivity of the virions by accumulating a cluster of mutations after several months of replications in the population [5]. Viruses have smaller genome size and therefore, are prone to accumulate mutations at a much higher rate when compared to other organisms with larger genome size. It has been shown that spontaneous mutation rate varies among viruses, compared to DNA viruses single-stranded RNA viruses (ssRNA) mutate faster. The mutation rates of ssRNA viruses are influenced by polymerase fidelity, proofreading, secondary structure, replication mechanisms, 
sequence, and access to post-replicative repair systems [6].

Table 1: Total number of SARS-Cov2 genomes sequenced from March-July 2020 which were used as resource for the studies

\begin{tabular}{|c|c|c|}
\hline Month & Country names & $\begin{array}{l}\text { Total number } \\
\text { of sequences }\end{array}$ \\
\hline March & $\begin{array}{l}\text { Australia, China, } \\
\text { India, USA + } 36 \\
\text { countries }\end{array}$ & 3357 \\
\hline April & $\begin{array}{l}\text { Australia, } \\
\text { Bangladesh, China, } \\
\text { India, USA +12 } \\
\text { countries }\end{array}$ & 2181 \\
\hline May & $\begin{array}{l}\text { Australia, } \\
\text { Bangladesh, China, } \\
\text { India, USA + } 6 \\
\text { countries }\end{array}$ & 635 \\
\hline June & $\begin{array}{l}\text { Australia, } \\
\text { Bangladesh, China, } \\
\text { India, USA + } 3 \\
\text { countries }\end{array}$ & 668 \\
\hline July & $\begin{array}{l}\text { Australia, } \\
\text { Bangladesh, USA }\end{array}$ & 43 \\
\hline
\end{tabular}

Comparative analysis based on more than 7000 genomes of SARS-CoV-2 indicated that the virus has very high mutation rate for various structural genes [7]. An accurate estimation of mutation rate of the viral genome is often considered complex [8]. The viral genome mutations are represented as substitutions per nucleotide per cell infection $(\mathrm{s} / \mathrm{n} / \mathrm{c})$, and the rate of mutation ranges from $10^{-8}-10^{-6} \mathrm{~s} / \mathrm{h} / \mathrm{c}$ for DNA viruses whereas the mutation rate for RNA viruses ranges from $10^{-6}-10^{-4} \mathrm{~s} / \mathrm{n} / \mathrm{c}$. Therefore, it could be argued that after several rounds of multiplication across a wide range of population zoonotic RNA viruses, such as SARS-CoV-2 may accumulate a wide range of mutations. Optimistically, we could believe that some of those mutations could result in loss of infectivity. In this study, we have calculated the mutation rate of specific proteins of SARS-CoV-2 over the last four months (April - July, 2020) and correlated with the death rate caused by COVID19 across various countries. We were able to show significant correlation between the mutation rates of a couple of proteins with the death rate. We have also proposed that with the calculated rate of mutation, COVID-19 pandemic may be significantly weakened by the end of this year.

\section{MATERIALS AND METHODS:}

\section{Genes and amino acid sequences}

For the current study, four structural and two nonstructural proteins of the SARS-CoV-2 were selected. The full length protein sequences of the six SARS-CoV-2 proteins were retrieved from the NCBI GenBank and the downloaded data were arranged month-wise for each of the proteins. A total of 41,304 SARS-CoV-2 protein sequences isolated from 49 different countries, deposited in the NCBI as of 31st July 2020 were utilized. Table 1 lists the number of protein sequences of the SARS-CoV-2 virus used in the current study.

Table 2: Covid-19 cases and deaths rate tabulated for the months March-July 2020

\begin{tabular}{|l|c|c|c|}
\hline \multirow{2}{*}{$\begin{array}{c}\text { Months } \\
(2020)\end{array}$} & \multicolumn{3}{|c|}{\begin{tabular}{c} 
Cumulative data of 49 countries of \\
\cline { 2 - 4 }
\end{tabular}} \\
\cline { 2 - 4 } cases \\
March & 687327 & $\begin{array}{c}\text { Number } \\
\text { of Deaths }\end{array}$ & $\begin{array}{c}\text { Death Rate/ } \\
1000 \text { cases }\end{array}$ \\
\hline April & 1490791 & 99428 & 50.35 \\
\hline May & 2507683 & 173926 & 69.69 \\
\hline June & 3434107 & 149320 & 43.48 \\
\hline July & 4746206 & 155342 & 32.73 \\
\hline
\end{tabular}

\section{Calculation of mutation rate}

By comparing the protein sequences of six SARS-CoV-2 structural and nonstructural proteins base pair differences were identified. Briefly, multiple sequence alignment (MSA) of each of the amino acid sequences of SARSCoV-2 proteins with their respective reference sequences of SARS-CoV-2_Wuhan (accession numbers YP_009725302, YP_009724396, YP_009724390, $\quad$ YP_009724393, YP_009724397, and YP_009724392) was performed using CLUSTĀLW with default parameters. The multiple sequence alignment helped in constructing an aligned view of query 
sequences based on an evolutionary relationship. Using the recorded variations corresponding to the reference amino acid residues a mutation profile was generated. Hence, an elaborative month-wise mutation profile for all the six proteins of SARS-CoV-2 was created. The mutation rate was calculated by taking a ratio of identified mutations from available sequences (the formulae as mentioned below).

Mutation Rate $=$ (Number of unique mutations / Number of SARS-Cov2 sequences) X 1000

\section{Calculation of death rate}

To analyze the death rate month-wise data for total cases and deaths over the period from March to July 2020 was derived from a web platform [9]. The month-wise death rate was calculated by simply dividing the number of deaths in a month by the number of cases reported for the month (the formulae as mentioned below). The complete calculated death rate is presented in Table 2 .

Death Rate $=$ (Number of deaths/ Number of COVID-19 cases reported) $\times 1000$

\section{Statistical analysis}

A correlation coefficient between the mutation rate and the global death rate for the six proteins was calculated using the Pearson's correlation method. Also, regression statistical analysis was performed on selected proteins using ANNOVA test.

\section{RESULTS AND DISCUSSIONS:}

\section{Selection of proteins for the study}

The viral RNA once inside the host cell encodes for both structural and nonstructural proteins. The structural proteins play an important role in host recognition and infection, whereas several non-structural proteins aid the process of replication and assembly of virion to enhance the infection efficiency. The genome of SARS-CoV2 consists of a single-stranded positive-sense RNA of $30 \mathrm{~kb}$. In the present study, four structural and two non-structural proteins were selected from 7195 genomes sequenced across different geographical regions, and analyzed for mutational changes for over last four months (March - June 2020).

NSP6: The non-structural protein 6 (NSP6) is a putative transmembrane protein translated from the largest gene (ORF1ab polyprotein) of SARSCoV-2, which is predicted to act as membrane anchor during assembly of the viral replication complexes [10]. The 290 amino acid residues long sequence of NSP6 protein, produced by both pp1a (polyproteins short) and pp1ab (polyproteins long) was downloaded from NCBI (YP_009725302). The mutation rate of NSP6 protein was observed to be 11.6 in March followed with a gradual dip in May (4.75) and then a rise June onwards (14.97). This was one of the two proteins where we noticed a higher mutation rate of 46.5 in July when compared to

\begin{tabular}{|l|c|c|c|c|c|c|}
\hline \multicolumn{6}{|c|}{ Regression Statistics calculated with death rate vs mutation rates } \\
\hline Protein name & NSP6 & ORF8 & S & M & E & $N$ \\
\hline Multiple R & 0.83 & 0.87 & 0.81 & 0.87 & 0.77 & 0.83 \\
\hline R Square & 0.69 & 0.76 & 0.62 & 0.76 & 0.59 & 0.69 \\
\hline Standard Error & 10.04 & 7.61 & 10.09 & 7.59 & 9.80 & 8.62 \\
\hline Observations & 5 & 4 & 5 & 4 & 4 & 4 \\
\hline P-value & 0.083 & 0.131 & 0.099 & 0.130 & 0.229 & 0.172 \\
\hline
\end{tabular}

Table 3: Regression analysis of mutation rate of structural and nonstructural proteins and global death rate are scored using ANNOVA 
the previous month. The number of unique mutations identified for the last 4 months were as follows April (23), May (3), June (10) and July (2). Previous reports have stated a significant role of L37F missense mutations in viral infection [11], in our analysis high frequency of occurrence of L37F mutation across all months was observed.

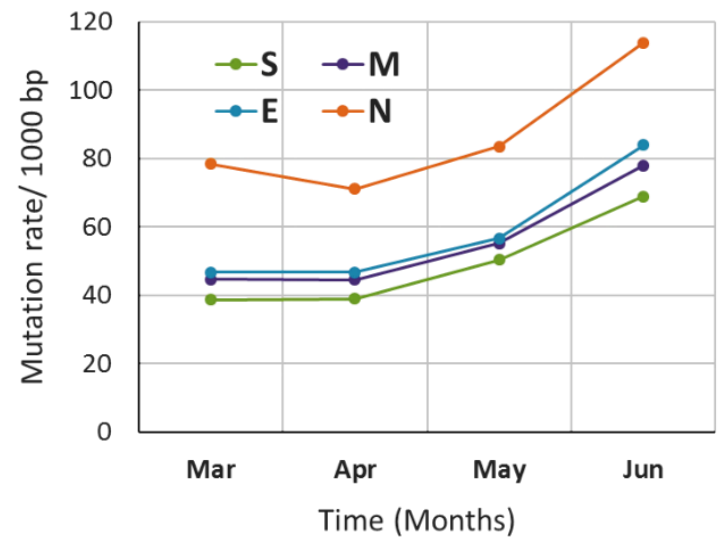

identified, maximum (328) unique mutations were encountered in $\mathrm{S}$ protein with 85 in April, 32 in May, 46 in June and 6 in July. The mutation having highest frequency across all months was D614G.

Membrane glycoprotein (M): The M protein (222 aa; UniProtKB - PODTC5; NCBIYP_009724393) is a component of the viral envelope which plays a central role in virus

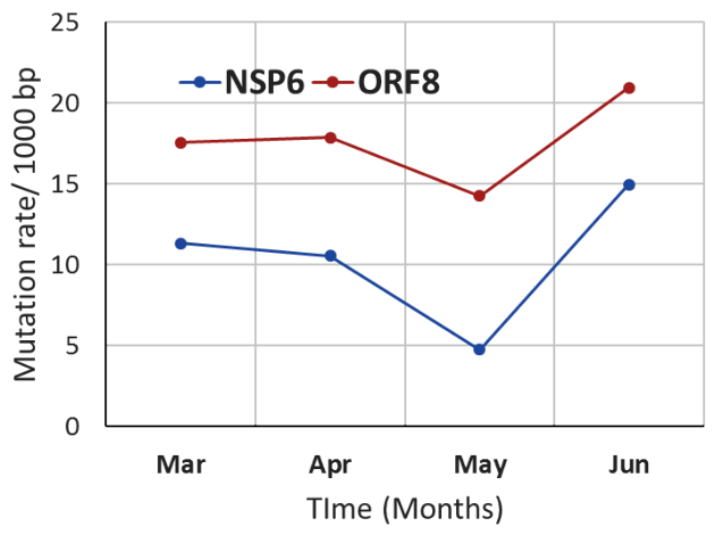

Figure 1: Analysis of the amino acid sequences of structural (A) and non-structural proteins (B) of SARS$\mathrm{CoV}-2$ is plotted in different months showing increase in mutation rate of the viral proteins from March Jun 2020 .

ORF8 protein (ORF8): The non-structural protein 8 (121 amino acid residues) is known to have a possible role in host-virus interactions (UniProtKB-P0DTC8; NCBI-YP_009724396). This protein showed variation in mutation rate ranging from 6.25 in March with a rise in April (7.34) and May (9.49). The two prominent mutations on position 24 with a change from serine to leucine and position 84 leucine to serine were observed across all months in ORF8 protein.

Surface glycoprotein (S): The longest of the four proteins, $S$ protein (1273 amino acids; UniProtKB-PODTC2; NCBI-YP_009724390) is involved in initiating the infection by interacting with the host's angiotensin-converting enzyme 2 (ACE2) receptor and therefore plays an important role in rapid/swift human to human transmission [Zhang et al., 2020]. It was noted from the line graph that $S$ protein showed a gradual increase in rate of mutation from 38.72 in March to 50.39 in July. This was the second protein wherein we observed that the July month mutation rate was higher (68.86) than the previous month. Out of the total mutations morphogenesis and assembly via its interactions with other viral proteins. In Fig 1, M protein is observed to have highest mutation rate (9.03) in the month of June.

Nucleocapsid phosphoprotein or Nucleoprotein (N): The N protein (419 aa; UniProtKB-PODTC9; NCBI-YP_009724397) holds a fundamental role during virion assembly through its interactions with the viral genome and $M$ protein, in enhancing the efficiency of sub-genomic viral RNA transcription as well as viral replication. For $\mathrm{N}$ protein the mutation rate in May was 31.57 which gradually decreased to 26.77 in June. The total number of identified mutations for $\mathrm{N}$ protein was 212, with 53 in April,17 in May, 20 in June and 0 in July with S194L mutation occurring dominantly across all months.

Envelope small membrane protein $(\mathrm{E})$ : The $\mathrm{E}$ protein is 75 amino acid (UniProtKB-PODTC4; NCBI-YP_009724392) similar to M protein, which plays a vital role in virus morphogenesis and assembly. It acts as a viroporin and selfassembles inside host membranes forming pentameric protein-lipid pores that allow ion 
transport. The mutation rate in the $\mathrm{E}$ protein was highest in June (5.98) and least in May (1.5)

The total number of unique mutations identified in all six SARS-CoV-2 proteins is represented using a mosaic plot. The Fig. 2, represents the unique mutations per $\mathrm{kb}$ of the genome in different months. Highest number of mutations were observed in $\mathrm{S}$ and $\mathrm{N}$ proteins. These 2 proteins being the longest out the six proteins, could be one of the possible reasons of accumulating more mutations.

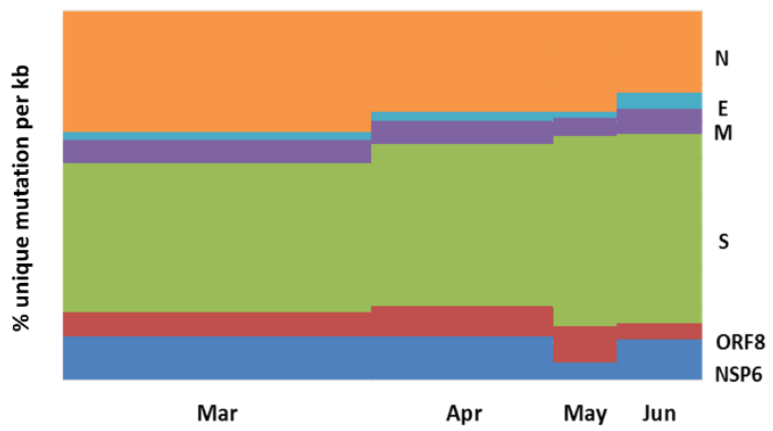

Figure 2: Month wise unique mutations of six proteins of SARS-CoV-2 showing highest amount of mutations in $\mathrm{S}$ and $\mathrm{N}$ gene per 1000 bp of genome

\section{SARS-CoV-2 genome data collection}

The amino acid sequences for the six viral proteins were retrieved from the $\mathrm{NCBI}$ (www.ncbi.nlm.nih.gov) and were segregated as per their genome sequencing date (March - July 2020). Table 1 lists the number of protein sequences of the SARS-CoV-2 virus used in the current study.

\section{Mutation analysis}

Protein sequences of SARS-CoV-2_Wuhan (accession numbers YP_009725302, YP_009724396, YP_009724390, YP_009724393, YP_009724397, and YP_009724392) were used as reference in this study. All these genomes were sequenced at China in the month of December 2019/ January 2020. Mutations in the six SARS-CoV-2 structural and nonstructural proteins were scored manually from multiple sequence alignment. A mutation profile that records all the variations corresponding to the reference amino acid residues was prepared for each of the protein and tabulated for all months. An elaborative month-wise tabulation of mutation profile for all proteins NSP6, S, N, E, M and ORF8 show a consistent increase over last three months (Fig 1).

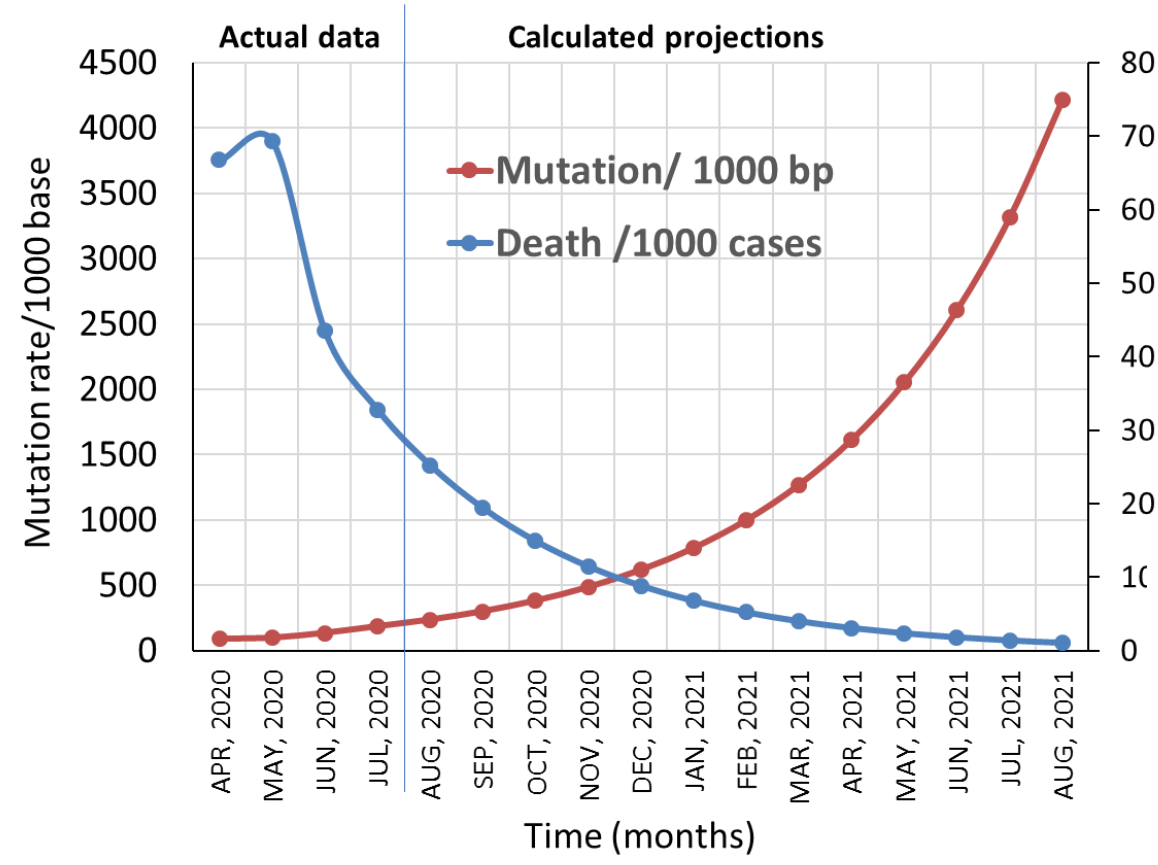

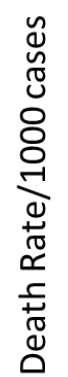

Figure 3: Cumulative mutation rate of the six proteins of SARS-CoV-2 and death rate of COVID-19 were ploted for April - June 2020 (actual data). Calculated mutation rate and death rate derived from slope were also ploted for Aug 2020 - Aug 2021 


\section{COVID-19 cases and death rate}

Month-wise data for total COVID-19 cases (infection) and deaths over the period from March to July 2020 were collected from a web platform [9]. The death rate per 1000 cases were derived and tabulated in Table 2. It was observed that the death rate was at its peak during May and showed a downward trend in June and July. This motivated us to compare the mutation rate with the death rate to draw our initial hypothesis that the death rate and mutation rate are inversely proportional.

\section{Comparative analysis of COVID-19 cases and death rate}

A comparative analysis of global death rate and cumulative mutation rates of all six proteins used in the study indicated that the death rate is inversely proportional with mutation rate. Slope for the death rate (1.29) and cumulative mutation rate $(0.79)$ were derived from the data of April, May and June. The slope value is used to calculate mutation rate and death rate, and the projected comparison is presented in Fig. 3. The data analysis clearly illustrated that by the month of November 2020 the cumulative mutation rate of the six protein will be close to $500 / \mathrm{kb}$ of genome which will lower the global death rate to $1.1 \%$.

Regression analysis is done to score the impact of mutation of each gene on the death rate (Table 3). Among the six genes used in the study, a significant positive relationship between the death rate (global) and mutation rate were noted in case of NSP6 and S proteins $[r(5)=$ $0.081-0.83 p<0.1]$. The $p$-value for ORF8 and
$M$ proteins are marginally higher $(p>0.13)$ than the p-value of NSP6 and S (Table 3).

As the p-value of NSP6 and S proteins were comparatively lower than other proteins $(\mathrm{M}, \mathrm{N}$, $\mathrm{E}$, and ORF8), the cumulative mutation rate of these two proteins was calculated with the death rate of three major clusters Cluster I (genomes sequenced from India and Bangladesh), Cluster II (genomes sequenced from United States) and Cluster III (genomes sequenced from Australia and New Zealand).

Analysis of the mutation rate and death rate was performed for these three clusters which is represented in Fig. 4. The cumulative mutation rate of NSP6 and S proteins are highest in cluster I, followed by cluster II and cluster III. Over last three months, sharp decline of death rate is also observed for cluster I and cluster III (Fig. 4). Independent analysis of the calculated death rate of these three clusters indicated that by the end of 2020 the death rate of cluster I will decline below $0.5 \%$, whereas the death rate of cluster III will be below $1 \%$, and death rate of cluster II will be around 1.5\% (Fig. 5). Therefore, it could be predicted from the analysis that in the cluster I countries (India and Bangladesh) the virion of SARS-CoV-2 will accumulate more mutations for NSP6 and S proteins and the death rate will be significantly reduced to $>0.5 \%$ by the end of 2020. As the rate of mutations of these two proteins are slower in cluster II country (USA) the calculated death rate of COVID - 19 will be $1-1.5 \%$ by the end of 2020 . It could be predicted that high mutation of NSP6 and S will result (a) defective virion assembly, (b) which
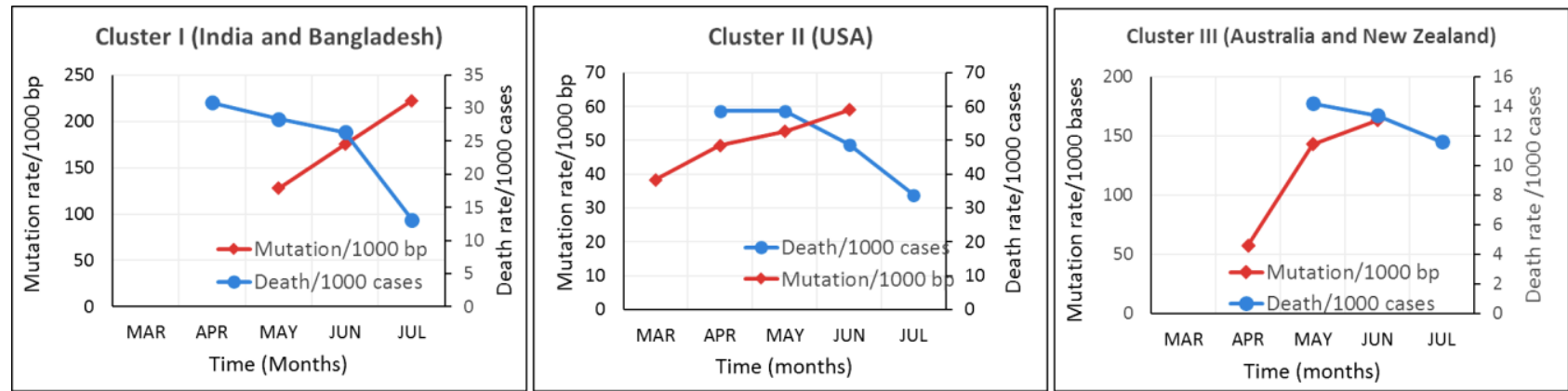

Figure 4: Cumulative mutation rate of the NSP6 and S proteins of SARS-CoV-2 and death rate of COVID-19 cases were ploted for three clusters (Cluster I, Cluster II and Cluster III). 
may inhibit subsequent infection, (c) negatively impact geometric progression of viral titer, and (d) lower death rate. Lower viral titer will provide competitive advantage to the host immune system to fight the infection efficiently.

\section{CONCLUSION}

There have been pandemic outbreaks in the past which affected larger populations of the world such as century-old Influenza pandemic or 1780s smallpox or other outbreaks from cholera in the 1830s to HIV-AIDS in the 1980s. But, on a positive note, there are lessons to be learned from the past. Firstly naming of the virus is important. For instance, naming coronavirus initially as Chinese flu gave the wrong indication of the limited spread of this disease to China only and thereby delayed the response to the pandemic threat. Secondly, social distancing is presently the only available preventive measure for this disease, lately, people have started behaving responsibly because of awareness and knowledge hence we can see a slight downward trend in death rate. Thirdly, one should be conscious that viruses can not only attack the old but younger population too, even though it is proven fact that the immunity compromised people are more vulnerable. Fourthly, one should not blame the person who falls sick rather he should be motivated to fight the virus out of his body and one should learn that global cooperation and knowledge sharing can help in times of outbreaks. Vaccination/immunization is the best solution one can have for such deadly infections and we are already on the track of developing it sooner. Lastly, we should believe in the fact that "this shall too end" as we are in the era of having advanced public health systems, scientific tools, and medical supplies, far superior to what we had in past.

The viral genome has undergone a series of mutational changes over the period since its parent genome has been released. In the current study, mutation rate of selected proteins was calculated in almost 7200 genomes of SARS-CoV-2 from 49 countries. Among the structural and non-structural proteins, NSP6 and $S$ showed high degree of correlation with death rate. Cumulative mutation rates of these two proteins showed high degree of correlation with the death rate in three focused clusters (I, II, III). All these studies have helped us to propose a hypothesis that, the mutation of these two proteins will grow consistently and the death rate will fall below $0.5 \%$ in cluster I countries (India and Bangladesh) by the end of 2020. The mutation rate of NSP6 and S proteins are lower in cluster II country (USA) than in cluster I and cluster III countries. Therefore, we propose that the death rate of COVID-19 pandemic in cluster III country will weaken later than cluster I and II countries.

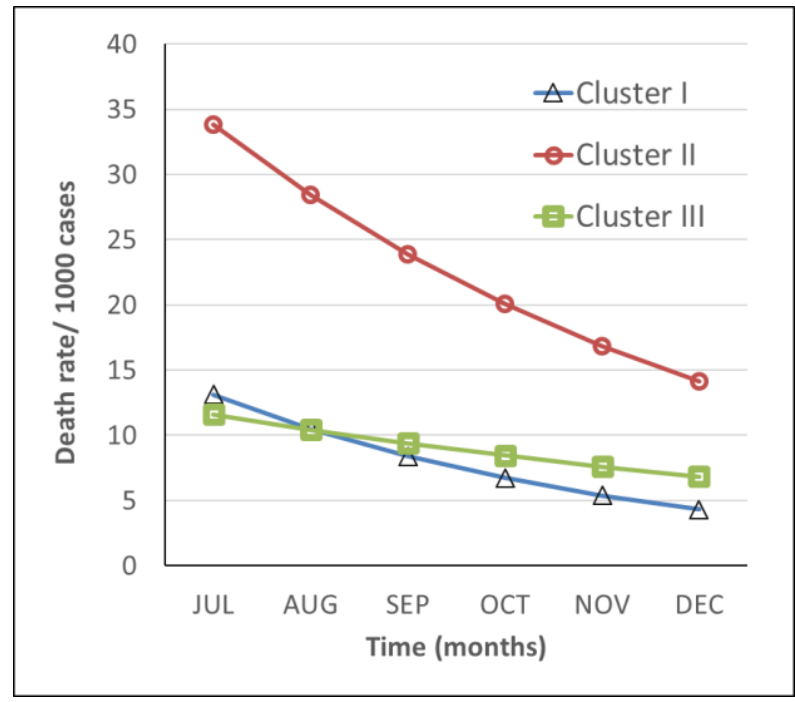

Figure 5: Calculated death rate (/1000 cases) were plotted for Cluster I, Cluster II and Cluster III countries. Cluster I= India and Bangladesh; Cluster $\|=$ USA; Cluster $\| I=$ Australia and New Zealand

\section{FUTURE RESEARCH SCOPE:}

We propose that a similar strategy of correlating country-wise mutation and death rates could be estimated in a big-data platform and Al models could be developed to eradicate COVID-19 pandemic in a much precise manner. In the model, integration of efficient treatment, epidemic management, and vaccination strategies could also be added on the mutation rate of structural and non-structural proteins (viz., NSP6 and S proteins). Country wise mapping of unique mutations in structural genes and docking studies could open windows on 
host - pathogen interactions, infectivity and mortality. This data could be used for developing personalize treatment strategies. The ongoing trials in vaccine development across the globe and progressive treatment methodologies will certainly contribute in the next quarter of the year and thereby we hope by end of this year, this pandemic will significantly weaken. In this scenario along with the frontline workers and researchers, people could also contribute by social distancing, using face mask, and following hygiene guidelines which will break the chain. This will reduce burden on the healthcare system and the society will develop herd immunity to further minimize the impact of the pandemic. Sequencing Monte Carlo sampling method were used to study the structural

\section{REFERENCES:}

1. P. Zhou, X.L. Yang, X. G. Wang, B. Hu, L. Zhang, W. et al., "A pneumonia outbreak associated with a new coronavirus of probable bat origin," Nature, vol. 579, no. 7798, pp. 270-273, 2020.

2. H. Yu, J. T. Wu, B. J. Cowling, Q. Liao, V. J. Fang, S. Zhou, P. Wu, H. Zhou, E. H. Lau, D. Guo, M. Y. $\mathrm{Ni}$, Z. Peng, L. Feng, H. Jiang, H. Luo, Q. Li, Z. Feng, Y. Wang, W. Yang, and G. M. Leung, "Effect of closure of live poultry markets on poultry-toperson transmission of avian influenza A H7N9 virus: an ecological study," Lancet (London, England), vol. 383, no.9916, pp. 541-8, 2014.

3. K. E. Jones, N. G. Patel, M. A. Levy, A. Storeygard, D. Balk, J. L. Gittleman, and P. Daszak, "Global trends in emerging infectious diseases," Nature, vol. 451, no.7181, pp. 990-3, 2008.

4. S. S. Morse, "Factors in the emergence of infectious diseases," Emerging infectious diseases, vol. 1, no. 1, pp. 7-15, 1995.

5. W. H. O. (World Health Organization), "IHR Core Capacity Monitoring Framework: Checklist and Indicators for Monitoring Progress in the Development of IHR Core Capacities in States Parties," International Health Regulations (2005) document, Reference WHO/HSE/GCR/2013.2, WHO, Geneva, 2013.

6. R. Sanjuán, and P. Domingo-Calap, "Mechanisms of viral mutation," Cellular and molecular life changes due to ongoing mutations of SARSCoV-2 for developing efficient management of the epidemic [12].

ACKNOWLEDGEMENTS: We sincerely thank Reliance Industries Ltd.

CONFLICT OF INTEREST: none

AUTHORS CONTRIBUTION: SD, proposed the idea and participated in critical review of the manuscript. BB, plan data analytics and developed hypothesis. SJ, generated data and analysis report. Both SJ and BB drafted manuscript. sciences: CMLS, vol. 73, no. 23, pp. 4433-4448, 2016.

7. R. Wang, Y. Hozumi, C. Yin, and G. W. Wei, "Mutations on COVID-19 diagnostic targets," Cornell University arXiv preprint, no. 2005.02188v1, 2020

8. R. Sanjuán, M. R. Nebot, N. Chirico, L. M. Mansky, and R. Belshaw, "Viral mutation rates," Journal of virology, vol. 84, no.19, pp. 9733-48, 2010.

9. M. Roser, H. Ritchie, E. Ortiz-Ospina, and J. Hasell, "Coronavirus Pandemic (COVID-19)," Published online at OurWorldInData.org. url: 'https://ourworldindata.org/coronavirus'(2020)

10. S. Baliji, S. A. Cammer, B. Sobral, and S. C. Baker, "Detection of Nonstructural Protein 6 in Murine Coronavirus-Infected Cells and Analysis of the Transmembrane Topology by Using Bioinformatics and Molecular Approaches," Journal Of Virology, vol. JVI.00254-09, 2009.

11. R. Wang, Y. Hozumi, C. Yin, and G. Wei, "Decoding asymptomatic COVID-19 infection and transmission," Cornell University, no. arXiv:2007.01344, 2020

12. S. W. K. Wong, "Assessing the impacts of mutations to the structure of COVID-19 spike protein via sequential Monte Carlo," Cornell University, no. arXiv: 2005.07550v2, 2020 